\title{
CONTRIBUIÇÃO DA REAÇÃO DE MICRO-HEMAGLUTINAÇÃO PASSIVA PARA O TREPONEMA PALLIDUM (MHA-TP) NO LIQUIDO CEFALORRAQUEANO AO DIAGNÓSTICO DE NEUROSSÍFILIS
}

\author{
ALUIZIO DE BARROS BARRETO MACHADO*-GILBERTO EDUARDO BASSI** \\ SUELI MATILDE DA SILVA *** - SANDRA GUGLIELMO***
}

\begin{abstract}
RESUMO - Foi avaliado o comportamento da MHA-TP em 25 amostras de líqüido cefalorraqueano (LCR) obtidas de pacientes com diagnóstico de neurossffilis (trupo NS) e em 7 amostras de LCR de pacientes com reações sorológicas reagentes para sifiłis (grupo RSS'+), comparando-o ao de outras reações treponêmicas e não treponêmicas. A MHA-TP foi reagente em todas as amostras do grupo NS, a reação de imunofluorescência (FTA-Abs) e a de fixaçăo de complemento de Wassermann (FCW) em 24 e a reação do V.D.R.L. (VDRL) em apenas 9. Nas 7 amostras do grupo RSS + o FTA-Abs foi reagente, a MHA-TP em 6 e a FCW e o VDRL foram não reagentes. A análise dos resultados permitiu a conclusão de que 0 diagnóstico clínico de neurossífilis deve ser complementado pelo exame do LCR através do estudo das células, do perfil proteico e da associação de reaçōes imunológicas treponêmicas e não treponêmicas. A MHA-TP foi tão sensível quanto o FTA-Abs e requereu menor prática técnica e interpretativa, contribuindo, quando associada a reaçōes não trepontemicas, ao diagnóstico de neurossifilis.
\end{abstract}

Contribution of micro-hemagglutination test for antibodies to Treponema pallidum (MHA-TP) in cerebrospinal fluid to neurosyphilis diagnosis.

SUMMARY - A quantitative micro-hemagglutination test for antibodies to Treponema pallidum (MHA-TP) was evaluated in 25 cerebrospinal fluid (CSF) samples obtained from patients with neurosyphilis (NS group) and in $7 \mathrm{CSF}$ samples of patients with reactive serologic tests for syphilis (STS + ). These data were compared to treponemal and nontreponemal tests. The MHA-TP was reactive in all of the $25 \mathrm{NS}$ group samples, the FTA-Abs and the complement fixation of Wassermann (CFW) were in 24 and the VDRI in only 9 . In the 7 STS + samples (STS+ group), the MHA-TP was reactive in 6, the FTA-Abs in all of them and the nontreponemal tests were nonreactive. Results analyses support conclusion the clinical diagnosis of NS must be complemented by cytoproteic dual and immunological treponemal and nontreponemal assays in CSF. The MHA-TP test was as sensitive as FTA-Abs and required less technical and interpretative skills, contributing in association to CFW to NS diagnosis.

As publicaçōes mais recentes concordam em duas afirmações sobre a neurossífilis: $O$ advento da penicilinoterapia promoveu redução marcante na sua incidência e o uso indiscriminado de antibióticos induziu a dificuldades maiores no seu diagnóstico clínico $3,14,17$. A atipia das formas clínicas atuais da neurossifilis e o número crescente da sua forma assintomática 6 tornaram imprescindivel seu diagnóstico laboratorial pelo exame do líquido cefalorraqueano (LCR) 18 que, segundo as normas do Center

Trabalho da Seção de Liquido Cefalorraqueano da Divisão de Laboratório Central do Hospital das Clínicas da Faculdade de Medicina da Universidade de São Paulo (FMUSP): * Mestre em Neurologia (FMUSP); ** Médico-Chefe; *** Biologista. 
for Diseases Control, é obrigatório em pacientes com suspeita clínica da doençá e recomendado para pacientes assintomáticos com sifilis que tenha mais de um ano de duração e para casos de diagnóstico e de controle de evolução de sífilis congênita 2. $\mathrm{Na}$ neurossifilis, doença modelo dos processos inflamatórios crônicos do sistema nervoso central, o dano da barreira hêmato - encefálica (BHE) é pequeno e, portanto, os fenômenos neuroimunológicos locais sinalizam melhor o dual citoproteico do LCR 12 . Esta sinalização torna-se evidente pelas alteraçōes do exame citológico e do perfil proteico e pela presença de anticorpos não-específicos e de anticorpos específicos. Os năo-específicos reagem com a cardiolipina e săo detectados por dois tipos de reaçōes nāo treponêmicas: a fixação de complemento de Wassermann (FCW) e a de floculação do V.D.R.L. (VDRL). Os anticorpos específicos reagem com o Treponema pallidum (TP) e, em nosso meio, são pesquisados no LCR pela reação de imunofluorescência indireta (FTA-Abs), a mais difundida pelos seus altos indices de sensibilidade e especificidade 1,5. A reação de hemaglutinação passiva para o TP, descrita por Rathlev em 196715 representou importante progresso no diagnóstico de sífilis devido a sua especificidade, a sua sensibilidade e ao seu baixo custo operacional. Estas vantagens foram confirmadas para o estudo de anticorpos treponêmicos no LCR $t$.

O objetivo deste trabalho é avaliar o comportamento da MHA-TP em amostras de LCR obtidas de pacientes com diagnóstico de neurossifilis e de pacientes com reações sorológicas reagentes para sífilis, comparando-a às reaçōes não treponêmicas FCW e à reação treponêmica FTA-Abs.

\section{MATERIAL E METODOS}

As 32 amostras de LCR estudadas foram divididas em dois grupos pela procedêneia: 25 foram obtidas de pacientes com diagnóstico de neurossífilis (grupo NS) e 7 de pacientes com reações sorológicas reagentes para sífilis (grupo RSS+). Em cadu amostra foram avaliadas: as caracteristicas do đual citoproteico quanto ao exame citolósico, às proteínas totais, à reaça coloidal de Takata-Ara: as reacōes FCW, VDRL, FTA-Abs e MHA-TP.

Os métodos usados e os resultados dos exames das amostras foram os adotados pela Seção de Líquíido Cefalorraqueano da Divisâa de Laboratório Central do Hospital das Clínicas da FMUSP $(1,4,9,16)$. Para a MHA-TP foi usada a técnica de Johnston ( $x$ ), com os reagentes Sera-Tek (Laboratório Miles do Brasil). Para os exames citológicos e do perfil proteico os resultados foram considerados como normal ou alterado. Para as reacōes imunológicas, os resultados foram dados como reagente ou não reagente para o FTA-Abs e, para as demais, foi anotado o título quando reagentes.

\section{RESULTADOS}

Os resultados do exame citológico e do perfil proteico nos dois grupos de amostras constam das tabelas 1 e 2 . As reações imunológicas reagentes do grupo NS e do grupo RSS+ foram distribuídas na tabela 3 e a associação entre as reações treponêmicas e não treponêmicas reagentes do grupo NS encontra-se na tabela 4. O comportamento dos títulos da. MHA-TP frente aos dois grupos é apresentado na tabela 5.

Exame citológico

Grupo NS

alterado normal total

\begin{tabular}{|c|c|c|c|c|}
\hline Perfil proteico & alterado & 7 & 8 & 15 \\
\hline & norma] & 3 & 7 & 10 \\
\hline & total & 10 & 15 & 25 \\
\hline
\end{tabular}

Tabela 1 - Distribuiçăo das 25 amostras do grupo NS quxnto ao exame citologico e no perfil proteico: grupo NS, grupo de amastras de pacientes com diagnóstico de neurossifilis. 


\begin{tabular}{|c|c|c|c|c|}
\hline \multirow[b]{2}{*}{ Grupo RSS+ } & & \multicolumn{3}{|c|}{ Exame citoløgico } \\
\hline & & alterado & normal & total \\
\hline \multirow[t]{3}{*}{ Perfil proteico } & alterado & 1 & 1 & 2 \\
\hline & normial & 0 & 5 & 5 \\
\hline & total & 1 & 6 & 7 \\
\hline
\end{tabular}

Tabela 2 - Distribuigāa das 7 amostras do grupo RSS+ quanto ao exame citológico e ao perfil proteico: grupo RSS+, grupo de amostras de pacientes com RSSt.

\begin{tabular}{ccccccc}
\hline Reaçós imunologicas & FCW & VDRL & FTA-Abs & MHA-TP & total \\
\hline & $\mathrm{n}(\%)$ & $\mathrm{n}(\%)$ & $\mathrm{n}(\%)$ & $\mathrm{n}$ & $(\%)$ \\
Grupo NS & $24(96)$ & $9(36)$ & $24(96)$ & $25(100)$ & 25 \\
Grupo RSS+ & 0 & 0 & $7(100)$ & $6(86)$ & 7 \\
\hline
\end{tabular}

Tabela 3 - Distribuicão drs amostras reagentes conforme a reação usada (FCW, fixação de complemento de Wassermann; VDRL, V.D.R.L.; FTA-Abs, imunofluorescencia FTA-Abs; MHA-TP, hemaglutimacão passiva para o Treponema pallidum) no grupo estudado (av. tabelas 1 e 2) em numeros absolutos (n) e percentuais (\%).

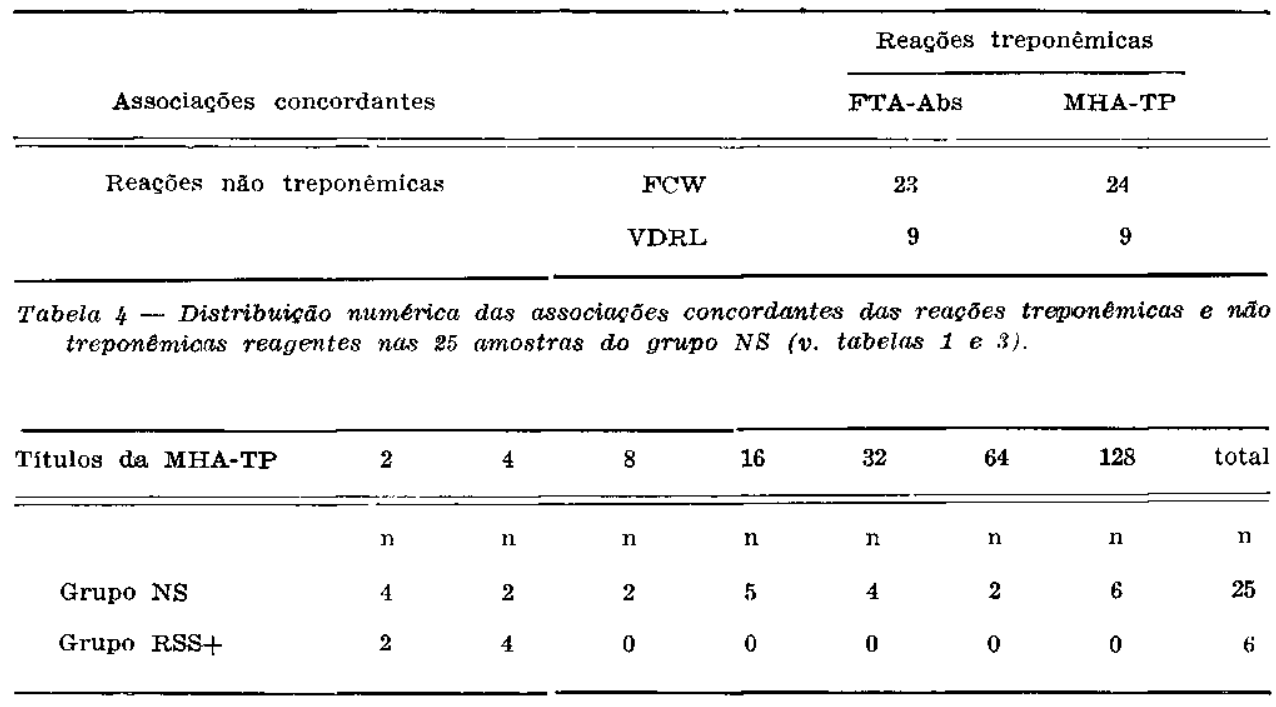

Tabela 5 - Distribução das 31 amostras MHA-TP reagentes pelo titulo da reação nos dois grupos estudados (v, tribelas 1, 2 e 3).

\section{COMENTÁRIOS}

A análise dos resultados quanto ao comportamento celular e proteico mostra as suas diferentes sinalizações nos dois grupos estudados. Em 18 das 25 amostras do grupo NS (72\%) houve alteraçóes no dual. sendo concomitantes em $7(28 \%)$, restritas ao exame citológico em $10(40 \%)$ e ao perfil proteico em $15(60 \%)$. No grupo RSS+ a sinalização foi observada em apenas 2 das 7 amostras, sendo que naquela en! 
que ambos os componentes do dual estavam alterados o paciente tinha o diagnóstico de mielite esquistossomótica. As informaçōes advindas do estudo das células e das proteinas dão conta do processo inflamatório crônico que o TP produz no sistema nervoso e estão de acordo com a literatura 12,14.

Quanto à comparação entre os resultados das reações imunológicas no grupo NS, a reação do VDRL mostrou-se muito pouco sensivel, sendo reagente em apenas $36 \%$ das amostras, fato que pode ser imputado à técnica adotada 4 . Entretanto, tem sido registrada com frequiência a superioridade da FCW sobre o VDRL no LCR 11,14, observação que pudemos constatar. Por outro lado, a alta sensibilidade descrita pará o FTA-Abs ${ }^{1,5}$ e para a MHA-TP 7,8 foi evidente no grupo NS, confirmando a contribuição dos testes treponêmicos ao diagnóstico laboratorial da neurossífilis. Nos 7 casos do grupo RSS + o FTA-Abs foi reagente, enquanto a MHA-TP foi reagente em 6. Tratando-se de reações que detectam anticorpos especificos, estes resultados devem ser atribuidos à passagem pela BHE de anticorpos treponêmicos séricos 7,13. As reações $F C W$ e do VDRL não apresentaram resultados falso-reagentes, informação já relatada por Lange 10 .

A associação de teste treponêmico de alta sensibilidade a teste não treponêmico é técnica recomendável ao diagnóstico de neurossífilis pelo exame do LCK. A associaçăo MHA-TP e FCW foi a mais concordante para o grupo NS. A avaliação dos títulos da MHA-TP, frente aos dois grupos de amostras, mostrou que no grupo RSS+ eles não ultrapassaram a 4 , enquanto no grupo NS os títulos foram superiores a 4 em $76 \%$ das amostras. Apesar da amostragem pequena, é possivel admitir que os anticorpos séricos nāo atravessam a BHE em niveis elevados e sugerir que títulos altos da MHA-TP no LCR são compativeis ao diagnóstico de neurossifilis.

As conclusōes deste estudo são que: a MHA-TP no LCR, quando comparada ao FTA-Abs, é igualmente sensivel e apresenta como vantagens as simplicidades técnica e interpretativa, além de menor custo operacional; associada à $\mathrm{FCW}$, contribui ao diagnóstico da neurossifilis.

\section{REFGRENCLAS}

1. Camargo ME, Bittencourt JMT - A reaçăo indireta de imunofluorescência para a sifilis no líqüido cefalorraqueano. Rev Paulista Med 69:15, 1966.

2. Center for Disease Control - Syphilis: recommended creatment schedules. Ann Intern Med 85:94, 1976.

3. Colli BO, Martelli N, Araújo LP, Barbieri J Neto - Goma sifilítica intra-raquídea causando compressāo medular. Arq Neuro-Psiquiat (Săo Paulo) 37:197, 1979.

4. Duncan WP, Bossak HN, Harris A - VDRL slide spinal fluid test. Am J Clin Pathol $35: 93,1961$.

5. Harris A, Bossak HM, Deacon WE, Bunch WLJr - Comparison of the fluorescent treponemal antibody test with other tests for syphilis on cerebrospinal fluids. Br J Vener Dis $36: 178,1960$.

6. Hooshmand H, Escobar MR, Kopf SW - Neurosyphilis: a study of 241 patients. J Am Med Assoc 219:726, 1972 .

7. Jaffe HW, Larsen SA, Peters M, Jove DF, Lopez B, Schroeter AL - Tests for treponemal antibody in CSF. Arch Intern Med 138:252, 1978.

8. Johnston NA - Treponerna pallidum hemagglutination test for syphilis: evaluation of a modified micro-method. Br J Vener Dis 48:474, 1972.

9. Kolmer JA, Spaulding EM, Robinson HW - Approved Laboratory Technic. Ed 5 . Appleton-Century Crofts, New York, 1951, pg 797-855.

10. Lange $O-$ Súfilis nervosa pré-clínica: contribuiçåo à profilaxia da sífilis nervosa pelo exame do liquäido céfalo-raquidiano. Tese. Săo Faulo, 1938.

11. Livramento JA - Contribuição de reaçōes de imunofluorescência no líqưido cefalorraqueano ao estudo da neurocisticercose. Tese. São Paulo, 1980. 
12. Livramento JA, Machado LR, Spina-França A - Sinalização do líqüido cefalorraqueano em doenças inflamatórias crônicas do sistema nervoso central. Arq Neuro-Psiquiat (São Paulo) 44:351, 1986.

13. Müller F, Kruska M, Hippius $H$ - tber Beziehungen zwischen immobilisierenden Antikörpern im Serun und Liquor cerebrospinalis. Z Neurol 198:237, 1970.

14. Nitrini $\mathbf{R}$ - Neurossífilis: análise de alguns aspectos clinicos e laboratoriais. Tese. São Paulo, 1981.

15. Rathlev $\mathrm{T}$ - Hemagglutination test utilizing pathogenic Treponema pallidum for serodiagnosis of syphilis. Br J Vener Dis $43: 181,1967$.

16. Spina-França A - Liquiido cefalorraqueano. In Tolosa A, Canelas HM (eds): Propedêutica Neurológica. Ed 2. Procienx, São Paulo, 1971, pg 443-465.

17. Zukerman E, Cardoso W, Di Migueli H, Reis-Filho I, Schwartzman JS, Bei A, Moreira MH, Giorgi DR, Rotberg A, Reis JB - Incidência de neurossifilis e de suas formas clínicas em São Paulo. Rev Paulista Med 70:270, 1967.

18. Zukerman E, Novo NF, Morgulis R, Reis-Filho JB, Barberini CH, Bertolucci PH Incidência da neurossifilis e frequêencia de suas formas clínicas no periodo 1962-1981. Arq Neuro-Psiquiat (São Paulo) 41:337, 1983. 